\title{
2D Geo-electrical imaging for shallow depth investigation in Doon Valley Sub-Himalaya, Uttarakhand, India
}

\author{
Param K. Gautam ${ }^{1}$ - Arkoprovo Biswas $^{1}$ (D)
}

Received: 26 August 2016/Accepted: 27 September 2016/Published online: 5 October 2016

(C) Springer International Publishing Switzerland 2016

\begin{abstract}
A 2D geo-electric profiling was executed close to Rajpur area in Doon Valley Sub-Himalaya, Dehradun, Uttarakhand. Profiling was executed at the site Civil Services Institute (CSI) close to Morvian Institute, Rajpur Road in Dehradun for possible shallow subsurface groundwater aquifer. Two resistivity and IP profiles were carried out to discover the conceivable groundwater zones in this area. It has been discovered that there are two inimitable palaeochannels found in these areas. These two channels act an erosional channel which was before happened to be a little stream. Beneath this, there is thick gravel and coarse sand stores in the close surface which is arranged at a profundity of $0.5-5 \mathrm{~m}$ with a thickness of $10 \mathrm{~m}$. This zone goes about as brilliant potential for shallow groundwater pockets. Besides, inside the surroundings of these rock stores, fine to medium sand is likewise present in the vast majority of the zones which also may likewise goes about as potential groundwater resources at a shallow depth. Notwithstanding, this groundwater pockets may not be adequate to address the issues of water in the mid year season and is very much prescribed to search for more profound aquifer in the study area.
\end{abstract}

Keywords Geo-electrical · Sub-Himalaya · Doon valley · Uttarakhand · India

Param K. Gautam

param@wihg.res.in

1 Wadia Institute of Himalayan Geology, 33, G. M. S. Road, Dehradun, Uttarakhand 248001, India

\section{Introduction}

One of the most precious natural resource which has important impact on human life, economic development of mankind (mainly in agriculture, industries etc.) and ecological diversity is the Groundwater. Out of the Earth's whole water systems, only a small fraction is suitable for human consumption (Bachmat 1994; Biswas et al. 2012). The presence of groundwater on the earth is the interaction of the geological, physiographical, hydrological and ecological factors (Biswas et al. 2013). In most of the groundwater studies, it is essentially a hydrogeological, remote sensing and geophysical presumption (Bachmat 1994; Biswas et al. 2012; Biswas et al. 2013; Sharma and Baranwal 2005; Sharma and Biswas 2013). This assumption is dependent on the correct elucidation of the hydrological and other geological indicators and evidences.

Exploration of groundwater has been studied using geoelectric and electromagnetic method which has been found to be very reliable for ground water studies over many years because of good correlation between electrical properties (electrical resistivity, conductivity, etc.), geology and fluid content (Sharma and Baranwal 2005; Sharma and Biswas 2013; Sharma et al. 2014). From a variety of electrical prospecting methods, a vertical electrical sounding (i.e. Schlumberger sounding) is successfully used for groundwater studies due to the simplicity of the technique, easy interpretation and rugged nature of the associated instrumentation. Moreover, electrical profiling, i.e. multi-electrode Wenner profiling, which is used for mapping lateral resistivity variations and is also useful for groundwater exploration (Owen et al. 2005). These techniques have been widely used in different geological conditions for various purposes (Van Overmeeren 1989; Urish 
and Frohlich 1990; Ebraheem et al. 1997; Mondal et al. 2008; Sastry and Mondal 2013; Biswas et al. 2014).

The multi-electrode resistivity strategy is currently genuinely settled as for hypothesis, functional application and understanding procedures (Barker 1981, 1992, 1996; Dahlin 1993, 1996; Loke and Barker 1996a, b; Loke 2000, 2004). Resistivity strategies are exceptionally delicate to varieties in earth resistivity, and are in this manner helpful for distinguishing lithological units and varieties inside lithological units. Such elements and changes are normally exceedingly noteworthy as for groundwater event. Ordinary DC resistivity sounding and profiling has effectively promoted on this part of resistivity reviewing however is feeble in appreciation of spatial scope. By using microcomputer control, the multi-electrode resistivity technique has overcome this shortcoming in resistivity surveying.

In the present study, the multi-electrode resistivity method has been used to assess the groundwater potential in Doon Valley which forms a part of Dehradun District in the North-western part of Uttarakhand state (Fig. 1a). We have reported the first operation of multi-electrode 2D resistivity and IP survey in Doon valley Sub-Himalaya, Dehradun, Uttarakhand to delineate the possible groundwater aquifer in the area.

\section{Regional geology}

The Doon valley has particular topographical properties with a wide range of rock sorts extending in age from Achaean to Quaternary (Thakur 1981). Taking into account the assortment of topographical procedures in time and space, the valley can be subdivided into two noteworthy physiographic-cum-tectonic units, viz. the Gangetic Alluvial Plain and Himalayan Mountain Belt. This valley reaches out from NW to SE and has a length of $80 \mathrm{~km}$ and a width of $18 \mathrm{~km}$. The valley catchment lies between latitudes $30^{\circ} 01^{\prime} \mathrm{N}-30^{\circ} 31^{\prime} \mathrm{N}$, and longitudes $77^{\circ} 38^{\prime} \mathrm{E}-78^{\circ} 19^{\prime} \mathrm{E}$, covering an area of about $1950 \mathrm{~km}^{2}$. The geology of Doon valley has been studied by various researchers (Philip 1995, 1996; Sati and Rautela 1998; Chandel and Singh 2000; Patel and Kumar 2003; Singh et al. 2001, 2004; Thakur and Pandey 2004; Thakur et al. 2007).

The valley is limited by Lesser Himalaya and Siwalik slopes in the north and south though the eastern and western part is shaped by Ganga and Yamuna streams, individually. The Gangetic alluvial plain zone comprises of Quaternary fluvial dregs. The subsurface examinations in this zone have uncovered a thick heap of alluvium resting similarly over the Siwalik progression of Neogene to early Pleistocene Period. The thickness of alluvium increments towards north and achieves its most extreme nearby the foot hill fault (FHF), which denote the northern furthest reaches of the most youthful foreland bowl in India i.e. the Ganga Fore profound Basin. The Ganga Fore profound silt stretch out up toward the south of depositional limit of the Siwalik progression and rests over Precambrian cratonic rocks of Peninsular Indian Shield.

The Himalayan Mountain Belt is a part of the worldwide versatile belt of Mesozoic to Cenozoic age that is accepted to have advanced through the joining of dynamic Indian Plate and uninvolved Eurasian Plate amid the landmass mainland lithospheric impact. Late Proterozoic (a)

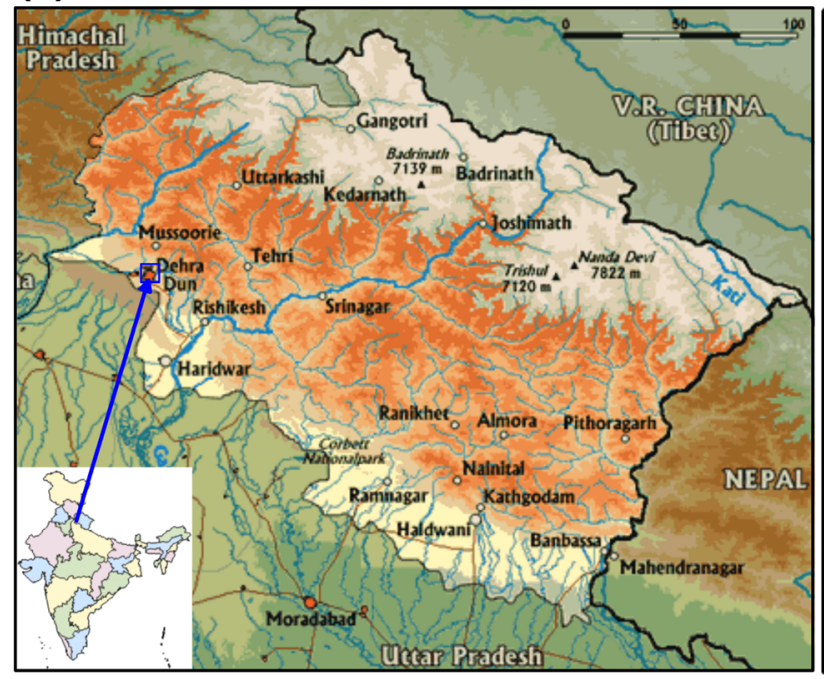

Fig. 1 a Location map of the study area; $\mathbf{b}$ generalized geological map of the study area (Doon catchment Valley). 1 Southern SubHimalayan belt of Siwalik, $2 a$ northern Sub-Himalayan belt of Siwalik, $2 b$ Lesser Himalayan belt, 3 Ganga River, 4 Yamuna River, (b)

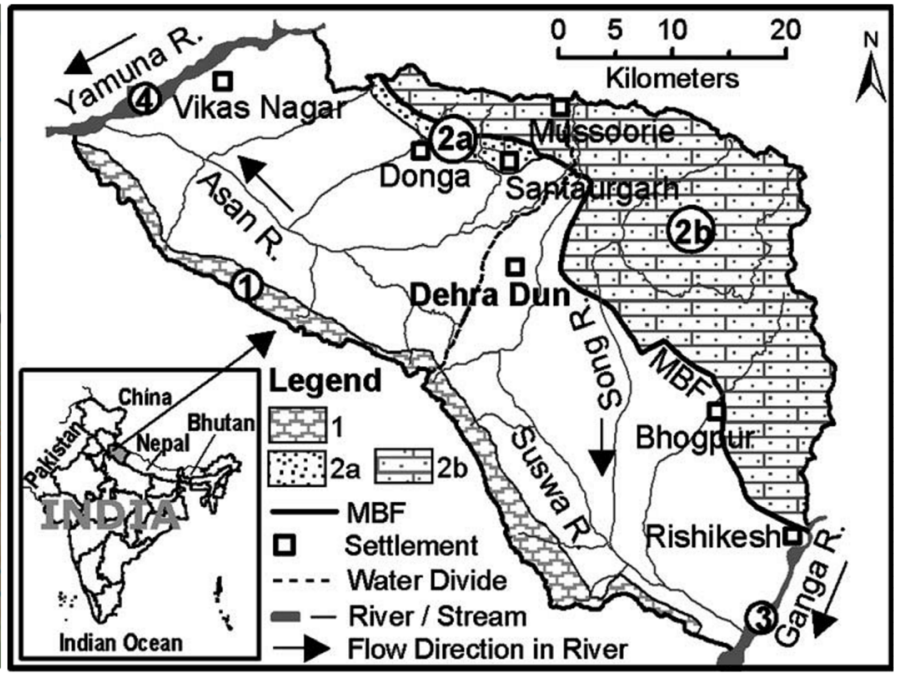

MBF Main Boundary Fault. Un-shaded area is the Doon Valley consisting of a large piedmont alluvial aquifer system (after Srivastav et al. 2007) 
(Neoproterozoic) to early Cenozoic crustal arrangements frame a little piece of Himalaya, though the fundamental mountain chain comprising prevalently of Proterozoic rocks speaks to a part of the Indian Shield. The Proterozoic crystalline rocks have been influenced by different orogenic scenes of Mesozoic to Cenozoic Period and hint at numerous periods of distortion and transformative nature. The extra-peninsular locale has a wide range of rocks of sedimentary, metamorphic and igneous origin.

Doon Valley goes under the Outer Himalaya or subHimalayan zone. This zone constitutes of a thick Cenozoic sedimentary heap running in age from Paleocene to Upper Pleistocene. Its northern and southern limits are delimited by the main boundary thrust (MBT) and the FHF otherwise called the main frontal thrust (MFT), separately. This zone comprises prevalently of mainland molasses dregs of Siwalik Group running in age from Middle Miocene to Upper Pleistocene. The Siwalik Group has been subdivided into the Lower Siwalik, Middle Siwalik and Upper Siwalik. The Lower Siwalik comprises of fine to medium grained sandstone, the Middle Siwalik is framed of medium grained sandstone with calcareous solidifications and sandy clay and the Upper Siwalik comprises overwhelmingly of combination with lenticular outcrops of sandstone and minor clay.

The focal part of the Doon Valley catchment is chiefly loaded with profoundly porous and permeable unconsolidated to-ineffectively united piedmont alluvial or fan stores of Late Pleistocene to Holocene age, which shape the expansive aquifer framework hidden the study territory (Fig. 1b). These valley-fill stores comprise of thick conglomerates beds with aggregates with pebbles and boulder sized clasts in a fine-grained matrix (Thakur and Pandey 2004), and are privately called the Doon Fan Gravels or Doon Gravels (DG). The Siwaliks of the Sub-Himalayan belt comprise of molassic residue, fundamentally combinations, sandstones, and muds, of Neogene period (Upper Miocene to Early Pleistocene).

\section{Hydrogeology}

The hilly condition of Uttarakhand can comprehensively be characterized into two hydrogeological administrations in particular Gangetic Alluvial Plain and Himalayan Mountain Belt. A wide variety in geography and landforms of the range offered ascend to differed hydrogeological set-up. The range is comprehensively partitioned into three hydrological units to be specific, the Himalayan mountain belt, the Siwaliks and the Doon alluvial fill (Doon rock). The present territory exists in the external Himalayan or sub-Himalayan zone. This zone is made overwhelmingly out of sandstone, ferruginous shale and clay and is more youthful in age when contrasted with alternate units of the belt. The general rise of the zone is less than $1000 \mathrm{~m}$ above mean ocean level. Because of the semi-combined nature of rocks, potential ground water bearing developments are available in zones, which have a decent weathered mantle and exceptionally cracked/jointed rocks. In the Siwaliks, various valleys have additionally been created as an aftereffect of tectonic exercises (e.g. Doon Valley), which are essential from the hydrogeological perspective. The Doon Valley was framed as an Intermontane Valley inside the Siwalik Group of rocks in a foreland proliferating push framework. The Lower, Middle and Upper Siwaliks are uncovered in the region, and the Doon Gravels, a post-Siwalik Formation, were saved with the advancement of the valley. The Doon Gravels are thickly had relations with coarse clastic fan store generally Pleistocene and Holocene age. The thickness of the alluvial fill is $\sim 300 \mathrm{~m}$ in the focal part (i.e. close to the valley hub) and $\sim 100 \mathrm{~m}$ in the upper/northern part (Thakur and Pandey 2004). The aquifer framework is multilayered in nature, as regularly found in alluvial stores. Groundwater is under unconfined conditions in shallow aquifers and under semilimited conditions in more profound aquifers (Roy 1991, 1995). The Central Ground Water Board has effectively developed 11 profound tubewells, with release going from 252 to 3197 lpm (liter per minute) in the Doon Valley of Dehradun region. The water levels in these aquifers range from $20 \mathrm{~m} \mathrm{bgl}$ (below ground level) in the southern part of the valley to around $100 \mathrm{~m} \mathrm{bgl}$ in the northern part (CGWB 2009, 2010).

\section{Methodology}

\section{Basic principle}

Both Electrical sounding and profiling are routinely utilized for groundwater exploration, and are all around portrayed in standard geophysical texts (Parasins 1962). To get a detailed picture of the subsurface, a point by point photo of the subsurface can be acquired by joining the 1D sounding and profiling information to give 2D cross sections, which can in turn be joined to give a $3 \mathrm{D}$ model of the subsurface. In such type of work, it is very much of time consuming and highly cumbersome. This has led to the improvement of multi-electrode resistivity system (Dahlin 1996). Such instrument involves the utilization of numerous electrodes, associated by means of multi-core links to an exchanging box, which thusly is associated with a DC resistivity meter. A PC convention document teaches the exchanging box to consequently choose blends of four electrodes at a period as indicated by the study outline, and the resistivity meter takes readings for every arrangement of chose terminals, in this way delivering a 2D information set. 


\section{Electrical resistivity}

This survey provides the subsurface resistivity distribution through the measurements on the ground surface. The ground resistivity depends on the various geological parameters such as mineral and fluid content, salinity of the contained water, porosity and degree of water saturation the subsurface materials (Sharma and Baranwal 2005; Sharma and Biswas 2013; Biswas et al. 2014; Biswas and Sharma 2016). The fundamental law of resistivity survey is Ohm's Law that governs the flow of current in the ground. The Ohm's Law in vector form can be defined as

$J=\sigma E$

where $\sigma$ is the conductivity of the medium, $J$ is the current density and $E$ is the electric field intensity. The resistivity $\rho$ is equal to the reciprocal of the conductivity $(\rho=1 / \sigma)$ and measure in ohm-meter. As the subsurface condition is inhomogeneous in actual, the measurements provides the apparent resistivity $\left(\rho_{\mathrm{a}}\right)$ of the medium which is calculated by

$\rho_{a}=k \frac{\Delta \phi}{I}$

$k=\frac{2 \pi}{\left(\frac{1}{r_{C I P 1}}-\frac{1}{r_{C 2 P 1}}-\frac{1}{r_{C 1 P 2}}+\frac{1}{r_{C 2 P 2}}\right)}$

where $k$ is the geometric factor that depends on the arrangement of the four electrodes, I is the current and $\Delta \phi$ is the potential difference, $r$ is the distance between the current electrode $(C)$ and the potential electrode $(P)$.

The subsurface resistivity is sensitive to type of material, water saturation and salinity of the contained water in the subsurface material. In this relation given a law and defend the resistivity as

$\rho=a \rho_{w} \phi^{-m}$

where $\rho$ is the rock resistivity, $\rho_{w}$ is fluid resistivity, $\phi$ is the fraction of the rock filled with the fluid, while $a$ and $m$ are two empirical parameters (Keller and Frischknecht 1966). For most rocks, $a$ is about 1 while $m$ is about 2 .

\section{Induced polarization (IP)}

In IP survey we measure the chargeability in milliseconds $(\mathrm{mV} / \mathrm{V})$, it is the ratio of amplitude of the residual voltage to the DC potential just after the current cut-off. In the time domain chargeability can be defined as

$m_{t}=1870 \frac{\int_{0.15}^{1.1} V_{s} d t}{V_{D C}}$

Apparent IP is calculated by two models using original and perturbed conductivities as
$m_{a}=\left[\phi\left(\sigma_{\mathrm{IP}}\right)-\phi\left(\sigma_{D C}\right)\right] / \phi\left(\sigma_{D C}\right)$

$\sigma_{I P}=(1-m) \sigma_{D C}$

where $\sigma_{D C}$ is the conductivity measured through the normal resistivity survey and effect of the chargeability is decrease the effectively conductivity to $\sigma_{I P}$ and $\phi$ is the calculated potential.

\section{Data acquisition}

2D geoelectrical resistivity imaging can be achieved by integrating the techniques of vertical electrical sounding with electrical profiling. It involves apparent resistivity measurements from electrodes placed along a line using a range of different electrode separations and midpoints. The procedure is repeated for as many combinations of current and potential electrode positions as defined by the survey configuration. 2D resistivity imaging can be seen as continuous vertical electrical sounding (CVES) in which a number of VES conducted in a grid are merged together or as a combination of successive profiles with increasing electrode spacing. Now a day's $2 \mathrm{D}$ resistivity surveys are usually carried out using large numbers of electrodes connected to multi-core cables and the area covered by the survey can be extended along the survey line using the rollalong technique (Dahlin and Bernstone 1997). A number of arrays have been used in recording 2D geoelectrical resistivity field data, each suitable for a particular geological situation.

In the present work, we collected resistivity-IP data along to two parallel profiles of $96 \mathrm{~m} \mathrm{A-B}$ and C-D through Multi-electrode resistivity imaging system "Syscal Pro-72" system of M/s IRIS Instrument France. As we were interested to obtain the horizontal as well as vertical lithological and ground water information on the basis of resistivity distribution, with this goal we chose WennerSchlumberger array (Griffiths and Turnbull 1985; Griffiths et al. 1990; Oldenburg and Li 1999; Olayinka and Yaramanci 2000) with $2 \mathrm{~m}$ electrode spacing at Rajpur site in Doon Valley Sub-Himalaya (Fig. 2). Total of 48 electrodes were used and electrodes were arranged along a line with a constant spacing of $2 \mathrm{~m}$ between the adjacent electrodes.

\section{Forward modelling and inversion}

RES2DMOD algorithm was used to forward modeling to calculate the apparent resistivity-IP pseudo-section for a user defined 2D subsurface model. The algorithm is based on least-square method involving finite-element and finitedifference methods (deGroot-Hedlin and Constable 1990; Sasaki 1992) and can support the user in choosing the appropriate array for different geological situations. This 


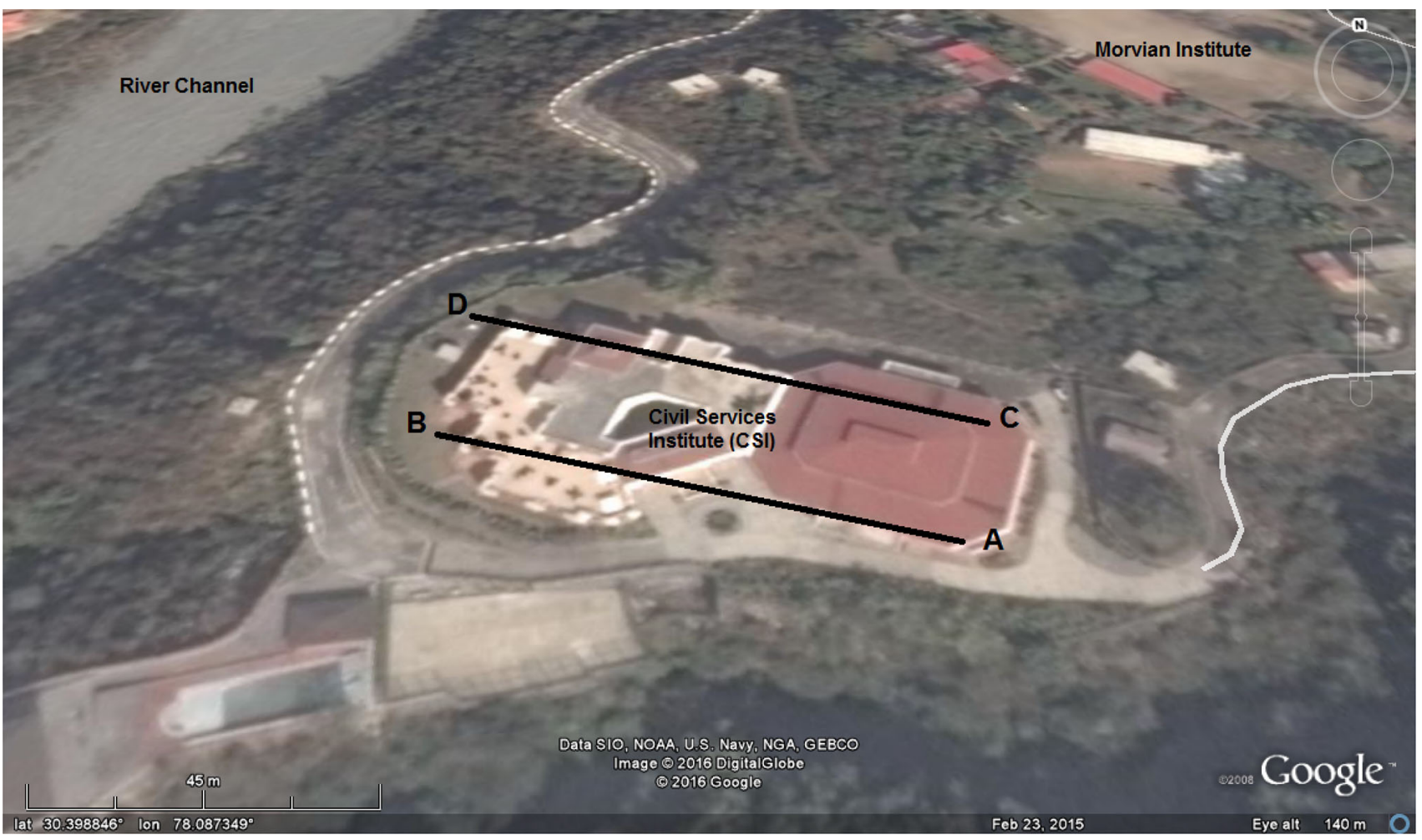

Fig. 2 Field Location Map of the study area with ERT profiles on Google map

program perform for almost all type arrays, however we have used Wenner-Schlumberger array for data acquiring in our study (Edwards 1977). In other hand to invert the data to produce continuous and seamless model, we used RES2DINV software. This utilized an iterative technique where starting from initial model and program tries to obtain improved model, whose calculated apparent resistivity values are closer to measured values (Loke 2000, 2004). The smoothness-constrained least-squares method is based on the following equation.

$\left(\mathbf{J}^{\mathbf{T}} \mathbf{J}+u \mathbf{F}\right) \mathbf{d}=\mathbf{J}^{\mathbf{T}} \mathbf{g}$

where

$\mathbf{F}=\mathbf{f}_{\mathbf{X}} \mathbf{f}_{\mathbf{X}}^{\mathbf{T}}+\mathbf{f}_{\mathbf{Z}} \mathbf{f}_{\mathbf{Z}}^{\mathbf{T}}$

$f_{x}=$ horizontal flatness filter, $f_{z}=$ vertical flatness filter, $\mathrm{J}=$ matrix of partial derivatives, $\mathrm{u}=$ damping factor, $\mathrm{d}=$ model perturbation vector, $\mathrm{g}=$ discrepancy vector.

\section{D high-resolution imaging}

The electrical resistivity is sensitive to lithology, intrinsic properties, porosity, fractures, degree and nature of fluids filling the pores, etc. The geo-electrical 2D model is assumed to vary both vertically and laterally along the survey line. The observed apparent resistivity values are commonly presented in pictorial form using pseudo-section contouring which gives an approximate picture of the subsurface resistivity distribution. The shape of the contours depends on the type of array used in the investigation as well as the distribution of the true subsurface resistivity. The pseudo-section plot serves as a useful guide for detail quantitative interpretation. Poor apparent resistivity measurements can easily be identified from the pseudo-section plot. The pseudo-depth values are based on the sensitivity values or the Frechet derivatives for a homogenous halfspace. All geological structures and spatial distribution of subsurface petrophysical properties are inherently three dimensional in nature. The three-dimensional effects of subsurface structures are more pronounced in environmental and engineering investigations where the geology is highly heterogeneous and subtle.

\section{Results and discussions}

The resistivity and IP images of the earth subsurface obtained at the study site Rapur, Doon Valley Sub-Himalaya is shown as the inverse resistivity and IP models in Figs. 3 and 4. The inverted geo-electrical sections were obtained through the optimization technique of RES2DINV by minimizing the difference between the calculated and measured the apparent resistivity values. The range of root 
(a)

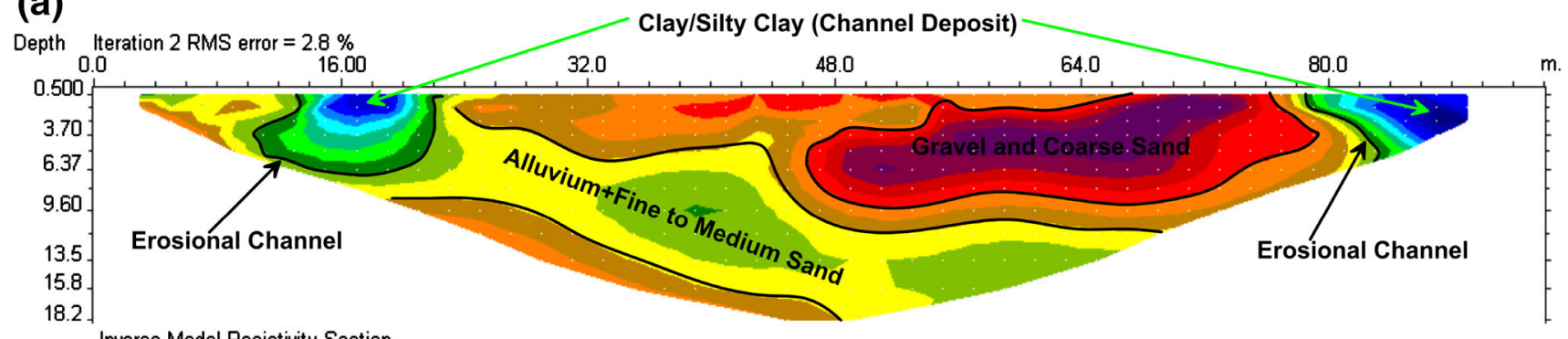

Inverse Model Resistivity Section

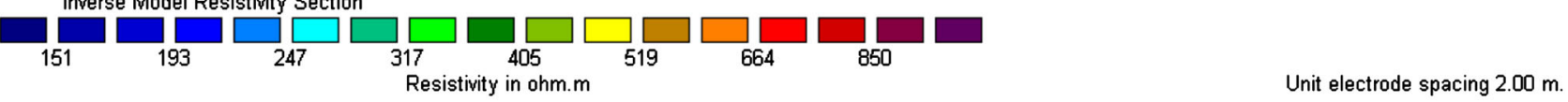

(b)

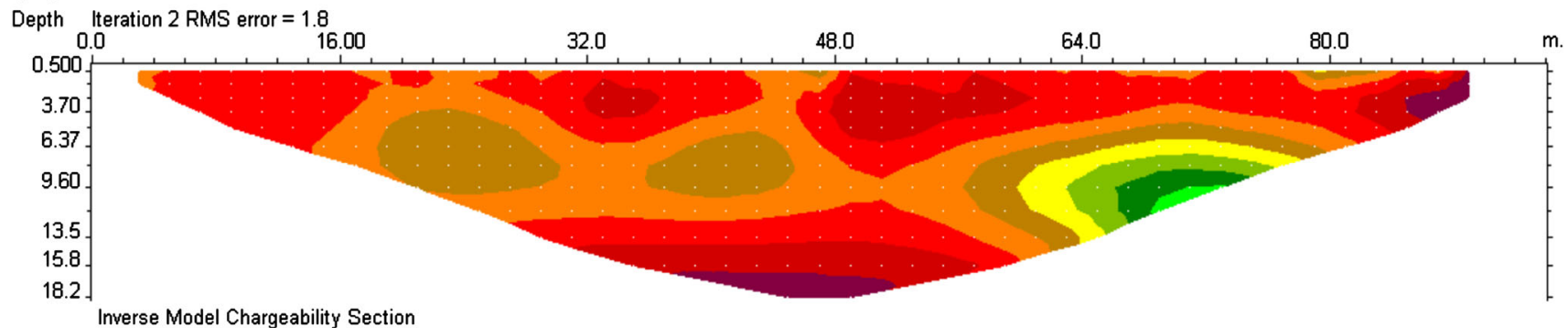

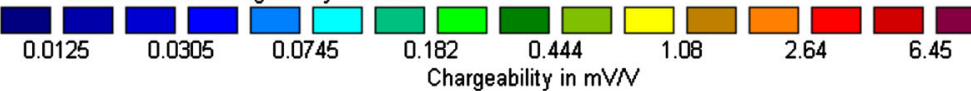

Unit electrode spacing $2.00 \mathrm{~m}$.

Fig. 3 Inverted 2D section for resistivity and IP-chargeability for Profile 1

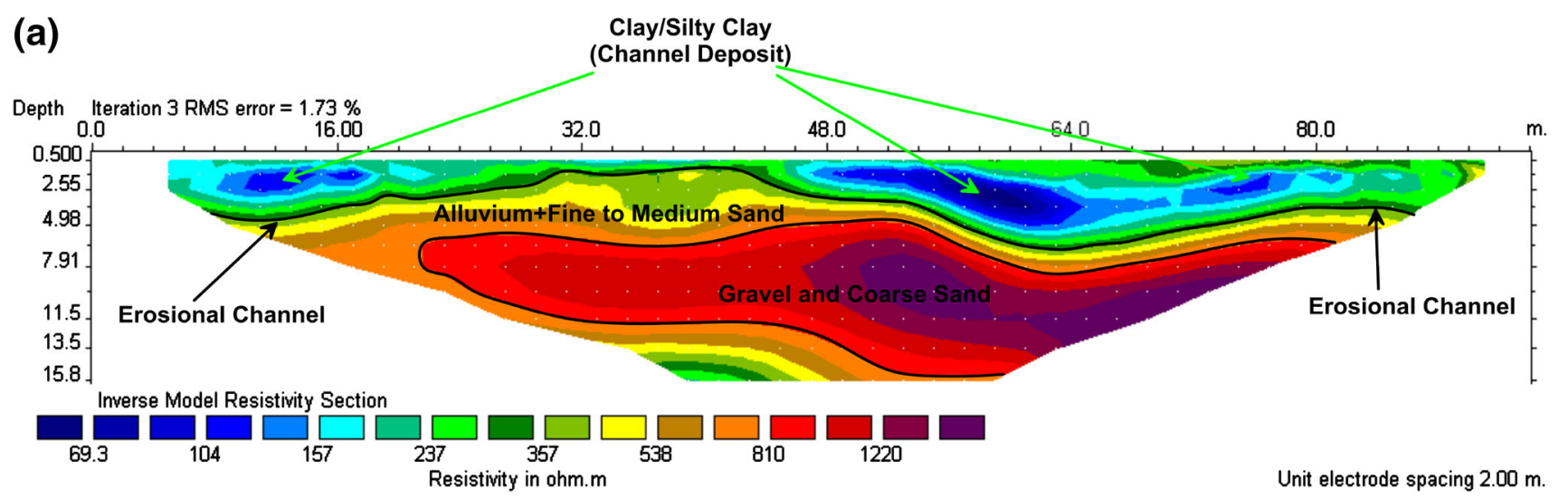

(b)

Depth Iteration 3 RMS error $=1.9$

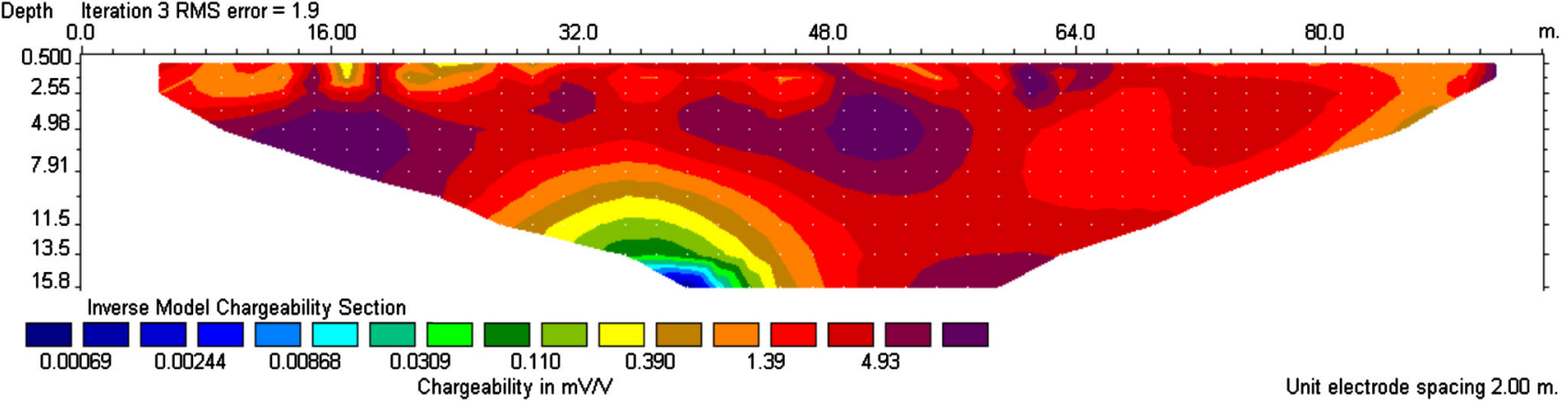

Fig. 4 Inverted 2D section for resistivity and IP-chargeability for Profile 2 
mean square error (RMS) of obtained inverse models is from 1.8-1.9 \% on iteration 2-3. The small range of RMS indicates a good correlation between the subsurface images depicted by the models. The models indicate the resistivity as well as IP variation upto the depth of approximately $20 \mathrm{~m}$ from the surface and covering an extent of $96 \mathrm{~m}$.

\section{Profile 1}

Inverted resistivity section (Fig. 3a) can be characterized lithologically on the basis of different resistivity values distribution. We observed wet silty-clay material upto the depth of approximately $7 \mathrm{~m}$ on either side of the profile under the electrodes from 12 to 24 and 74 to $88 \mathrm{~m}$ respectively and the resistivity range of this material is 151 to $250 \Omega \mathrm{m}$. Likewise, these two zones also show high chargeability (Fig. 3b). This layer was probably deposited in an earlier stream channels. Moreover, there is a clear demarcation of the Erosional channels in these two zones as marked in the figure. These were formed earlier and due to sediment deposition in those stream channels, it is now buried under the sediments or as palaeochannels. The near surface materials under the electrode distance from 24 to $48 \mathrm{~m}$ up to a depth of about $6 \mathrm{~m}$, have resistivity range of $500-650 \Omega \mathrm{m}$ is observed alluvium and medium sand deposits while the distance ahead from 48 to $72 \mathrm{~m}$ up to the depth of $10 \mathrm{~m}$ shows moderately high resistivity range from 650 to $900 \Omega \mathrm{m}$, which occupied with a thick deposit of gravel and coarse sand. This deposit is a probable zone of shallow groundwater pockets. Under this material it has been observed a $\sim 6 \mathrm{~m}$ thick fine sand layer with resistivity range $\sim 450-500 \Omega \mathrm{m}$ which is inclined at $\sim 30^{\circ}$ from horizontal. This layer starts from surface first electrode 2-68 $\mathrm{m}$ and extent up to the depth of $18 \mathrm{~m}$; it is also found some pockets of clay-sand materials having resistivity range of $400-450 \Omega \mathrm{m}$. This zone also acts as a potential groundwater source. The interpretations are validated with variation of chargeability at corresponding distance and depth in IP section shown just below of resistivity section.

\section{Profile 2}

Interpreted resistivity section (Fig. 4a) shows mostly clay to silty-clay deposit intermixed with sand at the near surface with prominent clay layers at 10-18 and 48-82 m respectively and the resistivity range of this material is 50-350 $\Omega \mathrm{m}$. This profile also shows a long erosional channel at a variable depth of 1-8 $\mathrm{m}$. This clearly indicates the presence of a buried stream channel or palaeochannels. Below this layer a very thick gravel and coarse sand deposit can be seen almost the whole of the profiles shows very high resistivity range from 800-1250 $\Omega \mathrm{m}$. This zone will act as an excellent potential for groundwater reservoir in this area. Moreover, this zone also shows high chargeability (Fig. 4b) because of presence of groundwater in the aquifers. This layer is surrounded by Alluvium with fine to medium sand deposit with its resistivity value ranges from 500-800 $\Omega$ m which may also act as a good groundwater reservoir. However, it is clearly evident that below a palaeochannels, it is expected to get a good groundwater aquifer within the subsurface. This is also evident from the first profile as shown above. Hence, it is highly recommended to trace the palaeochannels in this region to get a good groundwater aquifer in this region.

\section{Conclusions}

A 2D geo-electric profiling was carried out near Morvian Institute at CSI, Rajpur road in Doon Valley Sub-Himalaya, Dehradun, Uttarakhand. Two resistivity-IP profiles were obtained to delineate the possible groundwater body as well shallow sub-surface lithological variation in this region. The near surface is mostly covered with clay to wet silty clay deposits. Below this layer, a prominent clay layer is seen at a variable depth. It is also observed that the possibility of two prominent palaeochannels in the study area. These two channels act an erosional channel which was earlier happened to be a small river. Below this, there is thick gravel and coarse sand deposits in the near surface which is situated at a depth of $0.5-5 \mathrm{~m}$ with a thickness of $10 \mathrm{~m}$. These zone acts as an excellent potential for very shallow groundwater pockets. Moreover, within the surroundings of these gravel deposits, fine to medium sand is also present in most of the areas which may also acts as potential groundwater reserves. However, this groundwater pockets may not be sufficient to meet the needs of water in the summer season. Nevertheless, it is well recommended to look for deeper aquifer within the area to get a good amount of groundwater in the study area. It is also advisable to map the entire area for possible fracture/lineaments which could be a possible source of holding good amount of groundwater.

Acknowledgments Authors thank Prof. Anil Kumar Gupta (Director, WIHG) for providing the facilities, support and encouragement. Authors wishes to express their gratitude to all those who supported for data collection and processing etc directly or indirectly. We also thank Dr. Sushil Kumar (Head, Geophysics Group, WIHG), Mr. C.P. Dabral and Mr. Tajender Ahuja for their support during writing this paper.

\section{References}

Bachmat Y (1994) Groundwater contamination and control. Marcel Dekker Inc, New York 
Barker R (1981) The offset system of electrical resistivity sounding and its use with a multi-core cable. Geophys Prospect 29:128-143

Barker RD (1992) A simple algorithm for electrical imaging of the subsurface. First Break 10:53-62

Barker RD (1996) The application of electrical tomography in groundwater contamination studies. EAGE 58th Conference and Technical Exhibition Extended Abstracts, P082

Biswas A, Jana A, Sharma SP (2012) Delineation of groundwater potential zones using remote sensing and geographic information system techniques: a case study from Ganjam district, Orissa, India. Res J Recent Sci 1(9):59-66

Biswas A, Jana A, Mandal A (2013) Application of remote sensing, GIS and MIF technique for elucidation of groundwater potential zones from a part of Orissa coastal tract, Eastern India. Res J Recent Sci 2(11):42-49

Biswas A, Mandal A, Sharma SP, Mohanty WK (2014) Delineation of subsurface structures using self-potential, gravity, and resistivity surveys from South Purulia Shear Zone, India: Implication to uranium mineralization. Interpretation 2(2):T103-T110

Biswas A, Sharma SP (2016) Integrated geophysical studies to elicit the subsurface structures associated with uranium mineralization around South Purulia Shear Zone, India: a review. Ore Geol Rev 72:1307-1326

CGWB (Central Ground Water Board, Dehradun) (2009) Groundwater Management Studies. CGWB, Dehradun, p 22

CGWB (Central Ground Water Board, Dehradun) (2010) Groundwater exploration in Uttarakhand, pp 112

Chandel RS, Singh IB (2000) Morphostratigraphy and fan morphology of Doon Valley. J Indian Soc Rem Sens 28:265-274

Dahlin T (1993) On the automation of 2D resistivity surveying for engineering and environmental applications. Doctoral Thesis, ISRN LUTVDG/TVDG-1007-SE, ISBN 91-628-1032-4, Lund University, pp 187

Dahlin T (1996) 2D resistivity surveying for environmental and engineering applications. First Break 14:275-284

Dahlin T, Bernstone C (1997) A roll-along technique for 3D resistivity data acquisition with multi-electrode arrays. Process. SAGEEP'97 (Symposium on the Application of Geophysics to Engineering and Environmental Problems), Reno, Nevada, March 23-26 1997, vol 2, pp 927-935

DeGroot-Hedlin C, Constable SC (1990) Occam's inversion to generate smooth dimensional models from magnetotelluric data. Geophysics 55:1613-1624

Ebraheem AM, Senosy MM, Dahab KA (1997) Geoelectrical and hydrogeo- chemical studies for delineating groundwater contamination due to salt- water intrusion in the northern part of the Nile Delta. Egypt. Groundwater 35(2):216-222

Edwards LS (1977) A modified pseudosection of resistivity and induced-polarization. Geophysics 42:1020-1036

Griffiths DH, Turnbull J (1985) A multi-electrode array for resistivity surveying. First Break 3(7):16-20

Griffiths DH, Turnbull J, Olayinka AI (1990) Two-dimensional resistivity mapping with a computer- controlled array. First Break 8:121-129

Keller GV, Frischknecht FC (1966) Electrical methods in geophysical prospecting. Pergamon Press Inc, Oxford

Loke MH (2000) Electrical imaging surveys for environmental and engineering studies: a practical guide to $2 \mathrm{~d}$ and $3 \mathrm{~d}$ surveys. Retrieved from http://www.terrajp.co.Jp/lokenote.pdf

Loke MH (2004) Tutorial: 2-D and 3-D electrical imaging surveys. 2004 revised edition. Retrieved from http://www.geometrics.com.

Loke MH, Barker RD (1996a) Rapid least-squares inversion of apparent resistivity pseudosections by a quasi- Newton method. Geophys Prospect 44:131-152
Loke MH, Barker RD (1996b) Practical techniques for 3D resistivity surveys and data inversion. Geophys Prospect 44:499-523

Mondal SK, Sastry RG, Pachuri AK, Gautam PK (2008) High resolution $2 \mathrm{D}$ electrical resistivity tomography to characterize active Naitwar Bazaar Landslide, Garhwal Himalaya, India. Curr Sci 94(7):871-875

Olayinka AI, Yaramanci U (2000) Assessment of the reliability of 2D inversion of apparent resistivity data. Geophys Prospect 48:293-316

Oldenburg DW, Li Y (1999) Estimating depth of investigation in DC resistivity and IP surveys. Geophysics 64:403-416

Owen RJ, Gwavava O, Gwaze P (2005) Multi-electrode resistivity survey for groundwater exploration in the Harare greenstone belt, Zimbabwe. Hydrogeol. J. 14:244-252

Parasins DS (1962) Principles of applied geophysics. Methuen \& Co Ltd., London, pp 108

Patel RC, Kumar Y (2003) Geomorphological study of Quaternary tectonics of the Doon Valley, Garhwal Himalaya, Uttaranchal, India. J Nepal Geol Soc 28:121-132

Philip G (1995) Active tectonics of the Doon Valley. Himal Geol 6:55-62

Philip G (1996) Landsat thematic mapper data analysis for quaternary tectonics in parts of the Doon valley, NW Himalaya, India. Int J Remote Sens. 17(1):143-153

Roy AK (1991) Hydromorphogeologic mapping for groundwater targeting and development in Dehra Dun Valley, U.P. In: Gupta PN, Roy AK (eds) Mountain resource management and remote sensing. Surya, Dehra Dun, pp 102-107

Roy AK (1995) Water resources in Doon Valley: development and constraints related to hydrogeologic environment. J Himal Geol. 6(2):123-125

Sasaki Y (1992) Resolution of resistivity tomography inferred from numerical simulation. Geophys Prospect 40:453-464

Sastry RG, Mondal SK (2013) Geophysical Characterization of the Salna Sinking Zone, Garhwal Himalaya, India. Surv Geophys 34(1):89-119

Sati D, Rautela P (1998) Neotectonic deformation in the Himalayan foreland fold-and-thrust belt exposed between the rivers Ganga and Yamuna. Himal Geol. 19:21-27

Sharma SP, Baranwal VC (2005) Delineation of groundwater-bearing fracture zones in a hardrock area integrating very low frequency electromagnetic and resistivity data. Geophysics 57:155-166

Sharma SP, Biswas A (2013) A practical solution in delineating thin conducting structures and suppression problem in direct current resistivity sounding. J Earth Syst Sci 122(4):1065-1080

Sharma SP, Biswas A., Baranwal VC (2014) Very low frequency electromagnetic method - A shallow subsurface investigation technique for geophysical applications, In: Sengupta D (ed), Recent Trends in Modeling of Environmental Contaminants, Springer, Netherland, 119-141

Singh AK, Prakash B, Mohindra R, Thomas JV, Singhvi AK (2001) Quaternary alluvial fan sedimentation in the Dehradun Valley piggyback basin, NW Himalaya: tectonic and palaeoclimatic implications. Basin Res 13:449-471

Singh AK, Prakash B, Manchanda ML (2004) Tectonic geomorphology of the Dehradun Valley using digital terrain models and optically stimulated luminescence dating. Himal Geol 25(1):59-78

Srivastav SK, Lubczynski MW, Biyani AK (2007) Upscaling of transmissivity, derived from specific capacity: a hydrogeomorphological approach applied to the Doon Valley aquifer system in India. Hydrogeol J 15(7):1251-1264

Thakur VC (1981) An overview of thrusts and nappes of Western Himalaya. In: Price NJ, McClay KP (eds) Thrust and Nappe Tectonics, Geol. Soc. Lond. (Spec. Publ.), pp 287-392 
Thakur VC, Pandey AK (2004) Late quaternary tectonics evolution of Dun in fault bend/propagated fold system, Garhwal subHimalaya. Curr Sci. 87(11):1567-1576

Thakur VC, Pandey AK, Suresh N (2007) Late Quaternary-Holocene evolution of Dun structure and the Himalayan frontal fault zone of the Garhwal Sub-Himalaya, NW India. J Asian Earth Sci 29(2-3):305-319
Urish DW, Frohlich RK (1990) Surface electrical resistivity in coastal groundwater exploration. Geoexploration 26(4):267-289

Van Overmeeren RA (1989) Aquifer boundaries explored by geoelectric measurement in the coastal plain of Yamen- A case equivalence. J Geophys 54:39-48 